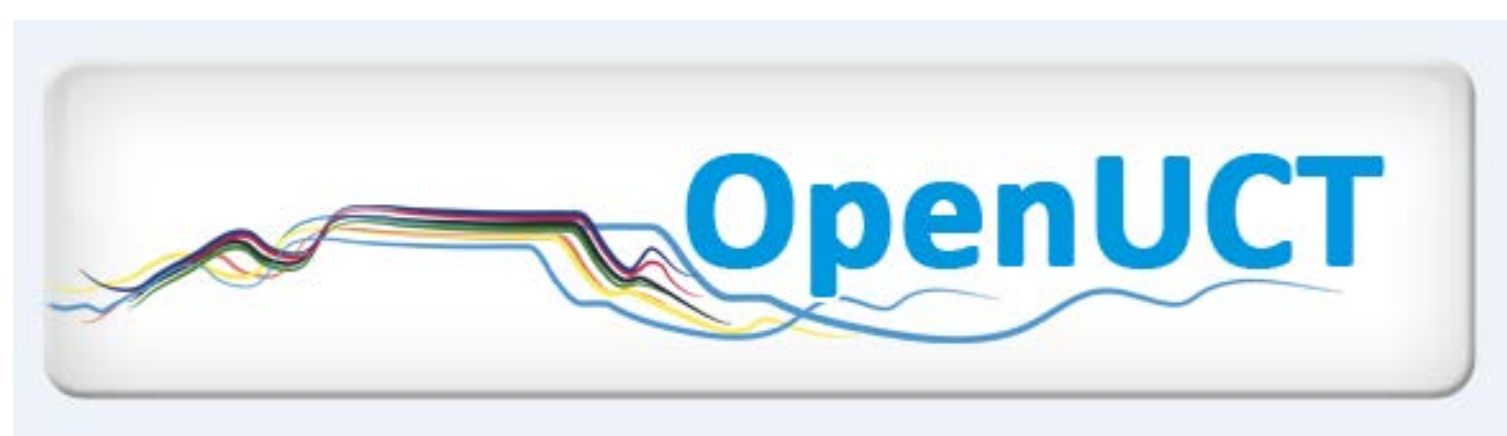

This is the post-print of Czerniewicz, L. 2010. Educational technology - mapping the terrain with Bernstein as cartographer. Journal of Computer Assisted Learning. 26(6): 523-534. DOI: 10.1111/j.1365-2729.2010.00359.x.

It is made available according to the terms of agreement between the author and the journal, and in accordance with UCT's open access policy available: http://www.openuct.uct.ac.za/sites/default/files/UCTOpenAccessPolicy.pdf, for the purposes of research, teaching and private study. 


\title{
Educational technology - mapping the terrain with Bernstein as cartographer
}

\author{
Laura Czerniewicz \\ University of Cape Town, South Africa
}

\begin{abstract}
:
This paper uses the literature of educational technology as the site of analysis in order to map the field of educational technology. Having considered Kuhn and Bourdieu's theories, the paper frames the analysis of the field in Bernsteinian terms as a horizontal knowledge structure in a vertical knowledge discourse. Using the concepts of interacting discursive planes, the paper maps the field in terms of its general approach planes and its problem planes. Finally, the paper shows that researchers in the field themselves acknowledge its weak grammar, and calls for commensurability of approaches to be acknowledged in order for robust knowledge to be developed and the legitimacy of the field to be enhanced.
\end{abstract}

Keywords: Bernstein, educational technology, field, higher education, knowledge.

\section{Introduction}

This paper describes the nature of educational technology in higher education terms of what it comprises; it has an epistemological focus rather than a socio-cultural one. Using a Bernsteinian framework, and drawing on a literature review, it maps the field as understood by professionals and scholars in the field itself.

The starting point for the mapping exercise is that a field of educational technology -by this or an associated name - does indeed exist, and that there is agreement regarding its existence internationally, from the United Kingdom (Seale and Rius-Riu 2001) and the United States (Ely 2000) in the north, to Australia (Alexander, Harper et al., 2006) and South Africa (Czerniewicz, Ravjee et al., 2006, Moll, Adam et al., 2007) in the south. It is known to be a young field (Conole, Dyke et al., 2004, De Vaney \& Butler, 1996b, Dueber, 2004, Jones, 2004, Luppicini, 2005); yet its location at the nexus of turbulent higher education times and ICT-mediated social transformation make it especially relevant.

The challenge is to describe the nature of this young field. How best might the terrain be mapped? An obvious lens for this task would seem to be Bourdieu's theories, especially given his well-articulated concept of a scientific field (Bourdieu, 2004).Indeed Bourdieu has been used to describe related and also emergent fields such as Educational Leadership (Lingard \& Christie 2003; Gunter 2001), Careers (Lellatchitch, et al 2003) and LIS (Library Information Systems) (Weller Haider 2007. An even more closely allied study is that undertaken by Menchik (2004) who used Bourdieu to consider educational technology in the schools sector. At least one higher education study using Bourdieu have recently been undertaken (Hudson 2009) although issues of field formation, community, power relations and legitimacy have also recently received attention, with the rules of the game being surfaced in overview reviews (Browne et al 2008, Shurville et al 2009). 
This socio-cultural focus on the field structured by both forces and struggles is both its strength and its limitation, as noted by Maton 2004, who points out that Bourdieu analyses 'who', 'where', 'when', 'how' and 'why', but not 'what'.

Given the epistemological focus, another theoretical option might be provided by Kuhn, particularly as interpreted by Masterman (1978). She suggests that rather than the usual pre-paradigmatic and mature sciences with which Kuhn is associated, it would be more useful to differentiate between the non-paradigmatic, dual paradigmatic and multi paradigmatic. This latter idea, the multi-paradigmatic, offers a way of describing educational technology given the tensions arising from the wide range of knowledge domains and disciplines informing the field: the human sciences; the learning sciences, the behavioural sciences, the physical sciences and the technological sciences.

This was not, however, a concept which Kuhn or Masterman pursued. In addition, Kuhnian paradigms are conceived as serial rather than simultaneous, with paradigms being split off from one another and without shared referentiality. It is interesting though, that the multi-paradigmatic concept may be considered a precursor to the Bernsteinian notion of specialist languages, as described later in this paper.

\section{Bernsteinian framework}

A Bernsteinian framework is used to map the epistemological dimensions of the field because his work offers precise tools for identifying and describing the structures, discourses and dimensions of the terrain. Bernstein's work is known for his contribution to issues relating to social class, language and educability and educational knowledge, pedagogy and social class (Edwards 2002). Particular attention has been paid to the way educational knowledge is produced and transferred, with most of the research addressing recontextualisation and pedagogy. Significant research has been undertaken using Bernstein's theorisation of knowledge discourses and structures, especially in maths education (Lerman, et al.2003 is but one example) but also in sites such as vocational education (Young 2006) and craft knowledge (Gamble 2004). His theorisation of discursive planes has been less utilised, a rare, and sensitive exception being a study in engineering education (Winberg 2007). Bernstein's work on knowledge structures has been critiqued, extended and elaborated by other scholars (such as Maton, 2000, 2006, 2007 and Luckett 2009). For the purposes of this paper, Bernstein's original formulations provided a nuanced way of describing the terrain, and it is this fine-grained teasing out of knowledge structures which are drawn on here.

In the first instance, Bernstein distinguishes between vertical discourses and horizontal discourses (Bernstein, 2000). A vertical discourse is a coherent, explicit systematically principled structure. It may be organised hierarchically or may take the form of a series of specialised languages with specialised modes of interrogation and specialised criteria for the production and circulation of texts. Horizontal discourses are everyday, oral, local and context-dependent. They are associated with the oral rather than the written, and with the forms of practical mastery and common-sense knowledge (Bernstein, 2000). They are therefore not useful for an analysis of a higher education field which, as a specialist language associated with the written form, would be a vertical discourse. 
More usefully (if confusingly) vertical discourses comprise hierarchical (also called vertical) knowledge structures and horizontal knowledge structures. A hierarchical knowledge structure looks like a triangle which integrates knowledge at the lower levels, showing underlying uniformities across a range of apparently different phenomena, creating general propositions and theories. Natural sciences traditionally would fall into this category.

Bernstein offers the concept of horizontal knowledge structures in hierarchical discourses; despite the potentially obscure sounding language this an especially cogent way of making sense of an emergent and applied discipline. Bernstein suggests that knowledge may be horizontally segmented, taking the form of specialised "languages" which co-exist, each with its own specialised modes of interrogation and specialised criteria. These "languages" make different assumptions, have different criteria for what counts as evidence and what counts as legitimate questions. Development in such a field takes the form of new languages which offer fresh perspectives and a new set of connections, rather than integration with existing theories and approaches.

In order to make sense of the various permutations and possible inter-connections within horizontal knowledge structures, Bernstein (1996) provides discursive planes explaining that a horizontal knowledge structure may contain two interacting discursive planes: the general approach plane and the problem plane. The general knowledge plane plays a theory role and is a space where metalanguages are produced to provide a basic orientation, a language of description and the rules which legitimize how phenomena are understood and interpreted. The general approach plane is segmentally structured and is made up of different theories. It is these theories in the general approach plane which determine what counts as a proper description. The specific problem plane is produced by the empirical study of particular problem areas. This plane is also segmentally structured by different problems and by different languages. The specific problem plane may develop a local context-specific language.

The interaction between the two planes adds subtlety to the inter-connections. Thus, a specialised language from the general knowledge plane may cut across a series of problems, or the same problem may be described by different specialised languages from the general approach plane.

In addition, Bernstein notes that under conditions of rapid social change what can be described may not describable or is only inadequately describable in a retrospective language. This fuels the fight for linguistic hegemony within a horizontal knowledge structure. There is an expectation of change which facilitates and legitimates attempts to add to the existing set of languages. It also encourages at a lower level of description idiosyncratic terms: all have the power of naming and renaming. The more contemporary the specialised, language and the greater the terms and syntax, the more it appears to create more relevant descriptions. 
Bernstein's observations help make sense of some of the difficulties faced by those within the field to "pin down" the field itself. The following sections map out the different dimensions of the field using Bernstein as a cartographer.

\section{What kind of terrain?}

The first consideration is whether educational technology integrates knowledge and shows uniformities across a range of apparently different phenomena, creating general propositions and theories or whether it comprises co-existing "specialised languages". Is it considered a vertical horizontal structure or a horizontal knowledge structure? Which is it?

\section{Educational technology as a vertical knowledge structure}

There is a small but powerful perspective which portrays educational technology essentially as a vertical knowledge structure. This "unity” view is framed by belief in consensus, and agreement about the nature and precepts of the field. Thus a confident statement from Dutch researchers asserts "the consensus about substantial elements of the knowledge base and about the nature of I.D [instructional design]”(Elen \& Clarebout, 2001 p.8). Related views align themselves even more closely with a Kuhnian version of a field which states that "Despite occasional ambiguities, the paradigms of mature scientific communities can be determined with relative ease” (Kuhn, 1962). The most explicit of these positions is expressed by Merril and the ID Group who insist that:

There is a scientific discipline of instruction and a technology of instructional design founded on this science. Like all science, the science of instruction is based on specific assumptions about the real world. The technology of instructional design is founded on scientific principles verified by empirical data. .... Instructional science is concerned with the discovery of the natural principles involved in instructional strategies; and instructional design is the use of these scientific principles to invent instructional design procedures and tools (Merrill, Drake et al., 1996 p.5).

A less dogmatic example is to be found in a paper presented to the IT Forum (an established online community), where researchers set out to firm up the foundations of the field. The authors invited the more than 2000 Forum members in 45 countries to "a dialogue about the specific language of instructional design and some new ideas we've developed about how to describe our field.” They "propose that Instructional Theory has now reached a level of development where a common knowledge base with a consistent terminology would greatly facilitate the future development of knowledge in this important area.” (Reigeluth \& Carr-Chelman, 2006 p1). It is interesting that the intention is to establish one common knowledge base, rather than, say, a shared research agenda. By implication, those drawing on different knowledge domains would remain outside of the field.

If one were to consider the field as characterised as a vertical knowledge structure one would consider the "real" field to be that most entrenched domain known as instructional technology, instructional design or, nowadays, as educational technology. Certainly such a domain exists, (although its changing or inconsistent name is telling). It is positivist in approach and method, based on instructivist (or more recently cognition) theories. It is most firmly located in the US although its spread is global and includes Europe 
and South Africa. It is described as having known, clear definitions, published by an acknowledged association, it has specified competencies as a profession, and agreed sources of research findings (Ely 2000).The extent of its historical reach is evident in the at least which have examined its identity as a field (Carr-Chellman, 2006). Books about the field such as field Instructional Technology, the Definition and the Domains of the Field (Seels \& Richey, 1994) and Educational Technology The Development of a Concept (Januszewski, 2001) assume that definitions and domains are known, shared "facts".

The implications of this positivist perspective are spelt out by its own proponents:

Those persons who claim that knowledge is founded on collaboration rather than empirical science, or who claim that all truth is relative, are not instructional designers. They have disassociated themselves from the technology of instructional design. We don't want to cast anyone out of the discipline of instructional science or the technology of instructional design; however, those who decry scientific method, and who deride instructional strategies, don't need to be cast off; they have exited on their own (Merrill et al., 1996 p.6).

This approach to the field might have the advantage of reassuring members that they are safely part of a community with clear parameters working in a knowledge domain founded on shared abstract foundations. It makes it easy to know whether a researcher or professional is "in' or "out”, thus providing a sense of legitimacy. However, it renders invisible the entire body of knowledge and field of practice with the same objects of study.

\section{Educational technology as a horizontal knowledge structure}

It is not a co-incidence that those argue for the field as a science make the arguments that would represent educational technology as a vertical knowledge structure. Similarly there are many who equate the challenges of the field with those shared by others in the social sciences. Thus, the observation that "the field of Educational Technology shares many of the same struggles in defining itself and substantiating its foundations, as do other social sciences and applied social sciences (Luppicini, 2005 p103) and the view that research into e-learning brings together a broad range of social science researchers (Whitworth \& Benson, 2004).

These tensions about science versus social science are allied with differences of opinion regarding whether the field is coherent and cohesive, or incoherent and fragmented. This latter representation is more prevalent, and can be usefully exemplified as a horizontal knowledge structure consisting of specialised "languages" with specialised modes of interrogation and criteria for the construction and circulation of texts. These "languages" are made up of a cluster of elements with criteria for legitimate texts, what counts as evidence, and what counts as legitimate questions.

From this perspective, instructional design is only one of the specialist languages of the field, which would then comprise other languages as well. Another significant "language" can be differentiated: Learning Technology. This cluster, bewilderingly also known as educational technology (as is the Instructional Design cluster from which is can be differentiated but with which it overlaps). Learning Technology is acknowledged as a 
field and a profession. Largely arising from the United Kingdom Learning Technology has also been explicitly defined (Seale and Rius-Riu 2001), is associated with a community, specific journals and at least one allied conference, all using the term "learning technology". Through the main association, accreditation for professional competencies has also been articulated through an accreditation scheme.

Another cluster which self differentiates is one known as Learning Science; in this instance the presumed overlap and the actual differentiation with Instructional Design has received attention by those in the field (Kirby, Hoadley and Carr 2005) ${ }^{1}$. Other distinct clusters can also be differentiated; another would be Computer Supported Collaborative Learning (CSCL) a field which self identifies as both a field (Chai \& S, 2006) and a community (Hoadley, 2005), but is unclear whether it is separate from, or a branch of the Learning Science (Dillenbourg, Baker et al., 1996). Yet another cluster with a fairly distinct identity - Networked Nearning -self describes as subscribing to socio-constructivist and collaborationist learning theories and tending to qualitative or mixed methods (de Laat, 2006, de Laat, Lally et al., 2005, Goodyear, Banks et al., 2004).

A completely different "take" is to be found in the 1990s in a self declared postmodernist cluster. This language is explicitly premised on post-modernist principles (Bryson \& de Castell, 1994, De Vaney, 1998, De Vaney \& Butler, 1996a, Hlynka, 2003, Hlynka \& A, 1992). The defining features here are for pluralism, criticism rather than evaluation, constant rethinking of beliefs and technology, a focus on power relationships as well as highlighting the relationship between corporate interests and technologies in the classroom (De Vaney, 1998, Hlynka \& A, 1992).

Precisely how these "languages" distinguish themselves, and where they overlap is a matter beyond this paper. The identified languages exemplify the groupings in the broader terrain. Just as in other fields such as sociology which are horizontal knowledge structures we see that "when disputes arise, a new specialised language is invariably invented because there is no generally accepted principle for integrating the existing disputing theories. Equally, there is no generally accepted means for clearing out old superannuated theories which begin to clutter the literature" (Moore \& Muller, 2002).

The literature suggests that the understanding of the majority of those working in the field would accord with the conceptualisation of a horizontal knowledge structure. There are, however, differing opinions as to whether or not this is a problem.

\footnotetext{
${ }^{1}$ In this citations study Kirby et al set out to discover the instructional design research and learning sciences research with their closely aligned interests, cited the same authors to any extent. The analysis, showed little overlap as measured by citations with only $2 \%$ authors publishing in both fields, and 0,5\% referencing the literature of the other field.
} 
For some researchers these differences are desirable, and the ability to work collegially drawing on multiple sources is an opportunity. Thus: "In reflecting on one's discipline it is important to draw on closely related and even distally related disciplines to both inspire new ideas and sharpen boundaries....A discipline that draws on its own practices as the primary inspiration of its research and theory risks stagnation and decline (Kozma, 2000 p11). This is echoed in the comment "there are often benefits in drawing theory from outside narrow educational confines and ... research will suffer unless this is done” (Perraton, 2000 p.4). Another practitioner is impatient with the inward focus, and asks whether the question should rather be how to promote a culture change to change the focus from "defining instructional technology" to identifying important issues to be studied (Duffy, 2003).

On the other hand, there is a concern that there is no one metatheory linking the disciplines feeding into the community of educational technologists or unifying the discipline internally. This might mean that educational technologists may only be familiar with "feeder disciplines", each of which has its own theoretical domain, and indeed these outlooks may be incommensurable (Jones, 2004). The danger is therefore that educational technologists with backgrounds as different in fundamental ways as computer science, information systems, linguistics, psychology and education may find themselves in clusters that are unable to communicate.

This raises an interesting question. Does a field structured as a horizontal knowledge structure automatically comprise incommensurate languages? And is it is accurate that verticality - which determines whether theories and explanations in a field are integrating or not - is a categorical principle as argued by some (Young \& Muller, 2007). This latter principle is binary (one either is or one isn't), rather than being on a continuum (less or more so).

Questions of coherence, integration and commensurability are central to a discussion of the nature of the field. Surely the lack of such a unifying theory and the existence of several "specialised languages" does not automatically mean that those clusters or languages are incommensurable? As Bhaskar notes, the very formulation of the problem of incommensurability presupposes common referentiality, that there is an object world in common (Bhaskar, 2002 p.12). He points out that the issue is not whether the object world is shared but the fact that it is described differently As becomes clearer in the next section, there is in fact agreement in the field about its object and its research agendas.

\section{Consistency and coherence of the terrain}

As explained earlier, two interwoven discursive planes provide a way of drawing out the various permutations and possible inter-connections within horizontal knowledge structures.

The specific problem plane, produced by the empirical study of particular problem areas may be segmentally structured by different problems and by different languages. It is in the specific problem plane that it becomes clear which problems are and which research 
questions are identified and distinguished. These are the groups of problems which the broader community considers worthy of attention and investigation.

Is there an agreed research agenda in educational technology? This question has received regular attention in the form of reviews of varying extents and depths in the UK (Beetham, 2005, Bernstein, 1996, Taylor, Rodden et al., 2004), the US (Pollard \& Pollard, 2005), Europe (Ballachef, 2006), South Africa (Van der Westhuizen, 2004) and Australia (Hedberg \& McNamara, 2002) . In fact, Beetham comments that priorities for e-learning research have never before been so widely debated (Beetham, 2005).

Hedberg and McNamara's (2002 p.118) comment that the themes of research in the early 2000s in Australia have more of a human than a technological focus is borne out by the reviews and agendas internationally. Interestingly learning issues are unanimously the key theme mentioned in both research reviews and priorities, in contrast to the perception that the field's focus is technology. Thus a USA Delhi study names learning as the first area (Pollard \& Pollard, 2005). Learning as a theme is elaborated upon in several other reviews, with specific kinds or aspects of learning being named. Collaborative learning is of special interest internationally; it is the one area of research specifically named, for example in a Taiwanese article (Tu \& Twu, 2002), but is also mentioned elsewhere (de Laat et al., 2005). Another specific aspect of learning is that of informal or nontraditional learning, this being mentioned in UK, European and Australian studies (Ballachef, 2006, Hedberg \& McNamara, 2002, Taylor et al., 2004). Related themes specifically mentioned are assessment and evaluation (Beetham, 2005, Pollard \& Pollard, 2005), and the role of the teacher and teacher-student relationships (de Laat et al., 2005, Pollard \& Pollard, 2005).

Issues relating to diffusion and innovation also receive particular mention (Ballachef, 2006, Beetham, 2005, Hedberg \& McNamara, 2002). Issues relating to inclusion, access, accessibility and the digital divide are also considered crucial, generally because they are considered insufficient (Beetham, 2005, Taylor et al., 2004, Van der Westhuizen, 2004). There are other macro level areas identified to do with the institutionalisation of education technology, and sociological issues are also evident (such as the digital divide in education). This is despite the fact that the unique angle is technology. Specific kinds of technology, technological trends and especially assumptions about technology receive far less attention in stated research areas.

In brief, in the specific problem plane there is perhaps a surprising agreement regarding research issues, themes and objects of attention. It is particularly striking that so few of these themes focus primarily on the technological but rather on the social, the organisational, and especially the pedagogical.

The general approach plane locates the theories of the field, and is the space where metalanguages are produced to provide a basic orientation, a language of description and the rules which legitimize how phenomena are understood and interpreted. The general approach plane is segmentally structured and is made up of different theories. It is these theories in the general approach plane which determine what counts as a proper 
description. In educational technology the general problem plane locates two distinct theoretical approaches - constructivism and instructivism - clearly, both based on psychological learning theories ${ }^{2}$. This observation is confirmed across the Atlantic: "What we have now is a mixed economy of information transmission and actiontheoretical forms of constructivism (Dillon, 2004 p.148) and "It is politic to say this is not a competition [between behaviourism and constructivism] but, rather, a matter of selecting the appropriate approach according to the objectives being sought" (Ely, 1999 p.307). It is enlightening that he goes on to say that "Not much has changed in this regard since 1970" (ibid).

The instructivist has two main models at its centre: the ADDIE Model and Gagne's Instructional Model. According to some writers, the ADDIE Model is considered the bible of the field, with its own body of literature and its own standards of expertise (Gordon \& Zemke, 2000) They describe it as "neat, lean, orderly, precise, scientific" (p.45). This approach has been the subject of attack and debate in the last decade, yet it is argued that it is the key conceptual framework of the field (Bichelmeyer, 2004). A related model approach which might be described as orderly, and which falls in the instructivist camp, is Gagne's Instructional Model which has been and continues to be influential. As one paper stated, "Even nowadays, most instructional designers accept the Gagné-assumption as one of the major assumptions or even axioms of the field (Elen \& Clarebout, 2001).

The centrality of such theorists is acknowledged even by those researchers who recognise that many have (or need to) move on. Thus, the belief that there has been no other equally forceful theory in the field is expressed in comments that state that in the past the work of Skinner and Gagne served as the impetus for hundreds and hundreds of empirical studies, and that since then there has been no new predominant theory that has driven research (Driscoll \& Dick, 1999). Even so, others argue that a continued reliance on these approaches would stultify the field: "Our field will have no future if our researchers do not see ways of pushing the boundaries of thinking and moving them forward...[writers such as] Gagne do not hold the keys to the future of educational technology” (Kozma, 2000 p.12).

At the same time there is a significant cluster of views, especially from outside the US, which places constructivist approaches at the centre of the field. The following comments are illustrative: "Most practitioners of ICT would say they work on a social constructivist context which takes account of the situatedness of learning (Lave and Wenger 1991) and its collaborative nature. (Dillon, 2004 p 139), and "Networked learning is a relatively new field of research endeavour in which there is a small body of empirical research. Much of this work is based upon theoretical perspectives such as social constructivism

\footnotetext{
2 One might observe that the theoretical trends described above echo closely those in the general field of education. At a glance however, it seems that in the field of education there has been a progression from behaviourist learning approaches to constructive approaches to social constructivist approaches. What is notable in the educational technology field is the extent to which these theories remain concurrent, with examples of each or clusters of these approaches being described as prevalent even with the past five years.
} 
and social learning theories (learning communities) that has been employed in HE course design” (de Laat et al., 2005).

This consensus does not appear as widespread in the US where the rise of constructivism is acknowledged, but believed to be less compelling: "Constructivism has been the most widely published and discussed new perspective of late but it has lacked the specificity that attracts researchers (Driscoll \& Dick, 1999 p15).

In addition to these two dominant learning theory approaches embedded in the psychological domain, there are also sociological theories which might form several sub clusters, including activity theory, actor-network theory and others. It is of note that the key theories subscribed to in the field are social theories rather than technological ones. Other than the ecological approaches there is widespread agreement about the relationship between education and technology, with meaning and the agency primarily in the social rather than in the technological. In this view, pedagogy is primary and the technology secondary. Overall the field if characterised by a social shaping approach as defined by Brey (Brey, 2003).

This review has only been able to provide a broad brush stroke account of the discursive planes, and there are certainly more complex and subtle mappings needed, in order to surface the variety of theories, approaches and methods which inform the field. The accounts to date have tended to focus on one aspect rather that the inter-connections of the segments of the planes. What does emerge though, is that the discursive planes - the general approach plane and the specific problem plane - provide a way of flexibly mapping the internal dimensions of horizontal knowledge structures. Such a map can makes visible the relationships, the shared interests, the differences, the tangents, the referents, the common areas and the networks within the field.

\section{How explicit is the map?}

How does one know that one is in the field of educational technology? How clear and how shared are the terms, concepts and rules? Bernstein (2000) refers to syntax and to grammar to discuss how overt and how blatant the features of the terrain are. He differentiates between horizontal knowledge structures with an explicit conceptual syntax capable of relatively precise empirical descriptions or of generating formal modeling of empirical relations, and those where the conceptual syntax is implicit and weak.

A strong grammar visibly announces what it is ${ }^{3}$. For the acquirer the passage from one theory to another does not signal a break in the language; it is simply an extension of its explanatory/ descriptive powers $(2000,164)$. The number of languages internal to any horizontal knowledge structure may be fewer in the case of a strong grammar than the number internal to a horizontal knowledge structure with a weak grammar ( (Bernstein, 2000) p166)

\footnotetext{
${ }^{3}$ Examples of strong grammars would be economics, linguistics and psychology
} 
A field with a weak grammar ${ }^{4}$ may not clearly announce itself. Bernstein expects that horizontal knowledge structures with weak grammars would generate speakers obsessed with issues of language which would in turn construct, destruct, affirm and reproduce the positional structure of a particular intellectual field. He notes that obsessive orientation is particularly pronounced where derivations form the specialised languages yield very weak powers of specific unambiguous empirical descriptions (Bernstein, 2000).

The most obvious example in educational technology is the existence of a multiplicity of terms. Some writers have indeed suggested that because the field is so young, researchers do not have the language to describe what they are observing (Dawson \& Ferdig, 2006); a new language is therefore being negotiated and created as the field develops in both specific locations and across different communities. Noting that different theorists use the same term to refer to different things and different terms to refer to the same things, Reigeluth and Carr-Chelman argue that vague and inconsistent language is impeding the growth of the field itself (Reigeluth \& Carr-Chelman, 2006). Agreeing that the terminology of educational technology has appeared under different guises at different times, Hedberg and MacNamara suggest that this relates to alignment with specific facets of the field dominating at different times (Hedberg \& McNamara, 2002). Yet a detailed analysis of the terminology of the field concludes by noting the subtleties which exist, "The information presented ...clearly points out that each group of the terms has its own nuances of meaning. Thus, it is not right to say, that the terms from different groups have the same meaning, rather subset relationships exist between them (Anohina, 2005, p100).

Researchers and practitioners also acknowledge deeper problems illustrating a weak grammar in the field. There is a shared view that concepts, terms relations and procedures are not explicitly and properly articulated. Researchers from quite different positions call for increased coherence. One researcher criticizes the poor relationship of question to methodology, and the interpretation of research findings on the basis of both, calling it “underwhelming”(Alexander et al., 2006 p.164). Several - from divergent theoretical perspectives -call emphatically for increased methodological rigour and standardisation in the field. Thus, a proponent of an ecological learning approach in Europe comments that TEL (technology-enhance learning) is very far from the point where the results of experiments can be shared reliably and that there is need for methodological standards, description and annotation of experimental data, benchmarks, test beds (Ballachef, 2006). This overlaps significantly with the those calling for a platinum standard (by quantitative researchers) calling for "code books and common heuristics" so that descriptors can be compared across studies (Dawson \& Ferdig, 2006 p.4).

The problem with a weak grammar is that empirical work may be associated with ideological positions rather than with explanations, as this lengthy quote explains persuasively:

In a subject where theories and methods are weak, intellectual shifts are likely to arise out of conflict between approaches rather than a conflict

\footnotetext{
${ }^{4}$ Other examples of weak grammars would be anthropology, sociology and cultural studies.
} 
between explanations, for, by definition, most explanations will be weak and often non-comparable, because they are approach specific. The weakness of the explanation is likely to be attributed to the approach, which is analysed in terms of its ideological stance. Once the ideological stance is exposed, then all the work may be written off. Every new approach becomes a social

movement or sect which immediately defines the nature of the subject by redefining what is to be admitted, and what is beyond the pale, so that with every new approach the subject almost starts from scratch (Bernstein, 1977, in Moore \& Muller, 2002 p.629).

According to writers such as Young \& Miller (2007), knowledge structures with weak grammars are deprived of a principal means of generating progress (or new knowledge) namely empirical disconfirmation. They say that grammaticality determines the capacity of a theory to progress through worldly corroboration. However, because grammaticality is an ordinal principle across a continuum of grammaticality within each category, (or perhaps even across the entire spectrum), it is possible for a stronger grammar to be achieved (Young \& Muller, 2007).

It is desirable for a horizontally segmented field to have a "strong grammar". And in effect this is what the call for more explicit and healthy research is about: methods, theories and approaches which are robust, which are clearly articulated and which are carried through systematically.

All this points to the shaking out of the field, and the complexity of its emergence in the light of the rapidly changing context of higher education, the rapid growth of technology, and the echoes and inter-relationships of change in higher education and ICT-mediated social practices.

\section{Conclusion}

A Bernsteinian framing of knowledge structures provides a useful way of describing the intellectual terrain of educational technology. It also provides a way of for researchers and professionals in the field to envisage its future.

One key issue is that of verticality; the argument has been made in this paper that the field of educational technology is not vertically integrated. The only way this might be a possible would be to accord the domain of Instructional Design/Technology the legitimate status of being the "true" version of the field, a decision which in fact cannot be made forcibly. Internationally there are no indications of this taking place organically either. Rather the field is being formed in response to and together with the massive social changes happening in present times.

As an emergent field, educational technology is generally being located in the social sciences, and like other social sciences it is segmentally divided, interacting internally in complex ways. There are beginning to be indications that the field is coalescing into more coherent clusters, with the different names and terms being used flagging dominant focus 
areas, interests or assumptions. There is some agreement about the problems and the objects of researchers' gazes.

It is unsurprising that so many dimensions still in the process of being formulated given the complex nature of the work and the knowledge drawn on and generated. This is especially the case in the light of the unstable shifting foundations of the social digital spheres in which educational technology practices are more broadly located.

Since there are so many aspects of the work that are little understood and which are in the process of being named, formulated and investigated, it is important for researchers to recognise and operate with different world views, especially when working with the range of disciplines in which educational technology practice is located. A commitment to respect and open mindedness across existing clusters and sub groupings will serve the interests of the educational technology research community and strengthen the work undertaken in this emergent scholarly field.

This speaks to the issue of grammaticality. It is clear that researchers in the field are cognisant of the need for and committed robust and consistent research, the ability to incisively match questions with appropriate theories and methods. This plea for both a more explicit “conceptual syntax” and a mutual respect for different “"'ideological””, positions are indications of a shared commitment to a stronger grammar. Colleagues working in cultural studies and sociology, fields with similar challenges to those faced by those in educational technology, are eloquent, imagining a coherent and collegial field. They imagine "an intellectual field comprising a range of languages, constituted by schools of theory, methodological approaches, definitions of problems and interests, established bodies of knowledge, etc”. They add:

... though the approaches, substantive topics and methods of this kaleidoscope of people differ, they are able to speak to each other, to discuss and contest issues and ideas. Debates, arguments, disputes may rage at various moments, but within an atmosphere of mutual understanding. They have, in other words, established criteria and procedures sufficiently explicit for collective decisions to emerge as to which particular perspective most adequately accounts for what is agreed to be the case. This field of 'perspectives' is a field of specialisms but one which employs (or aspires to) a language of mediation between levels and between approaches. Macros and Micros speak to each other through a particular kind of grammar (more or less explicit or systematic) that enables them as a community to retain a sense of inclusiveness that transcends their specialist intellectual differences and so engage in the task of theoretical and substantive integration (Moore \& Maton, 2001).

It would be a serious loss to researchers in the educational technology field if the languages of the field were indeed considered incommensurable given the pressing need to make sense of the changing terrain and the shared commitment to using technologies to improve pedagogy and student learning. In order to build knowledge, there needs to be a conscious acknowledgement of commensurability. There is a crucial distinction to 
be made between considering the field to have different perspectives rather than different paradigms. While paradigms tend to be mutually exclusive, perspectives suggest a shared interest in solving common problems, albeit in different ways, and a commitment to mutual understanding using different approaches. Different perspectives have the potential to shed light on overlapping or mutual problems. Indeed, to give the last word to Bernstein: "The view would be markedly improved if the discursive centre of gravity shifted from the specialised languages to issues of empirical description, a shift from a commitment to a language, to dedication to a problem and its vicissitudes”.

\section{References}

Alexander, S., Harper, C., Anderson, T.D., Golja, T., Lowe, D., McLaughlan, R., Schaverien, L. \& Thompson, D. 2006. Towards a mapping of the field of elearning in: E. Pearson \& P. Bohrman (Eds) Edmedia World Conference on Educational Multimedia,Hypermedia \& Telecommunications (Orlando, )

Anohina, A. (2005). Analysis of the terminology used in the field of virtual learning. Educational Technology \& Society, 8 (3), 91-102.

Ballachef, N. 2006. 10 issues to think about the future of research on TELKaleidoscope Collective Working Paper).

Beetham, H. 2005. "e-Learning Research", ALT-J, 13(1), pp. 81-89.

Bernstein, B. 1977. Class, Codes and Control (London, Routledge).

Bernstein, B. 1996. Pedagogy, Symbolic Control and Identity (London, Taylor and Francis).

Bernstein, B. 2000. Pedagogy, Symbolic Control and Identity (Revised Edition) (Lanham, Boulder, New York, London, Rowan and Littlefield).

Bhaskar, R. 2002. From Science to Emancipation, Alienation and the Actuality of Enlightenment (New Delhi/Thousand Oaks/London, Sage Publications).

Bichelmeyer, B. 2004. The ADDIE Model” - A Metaphor for the Lack of Clarity in the field of IDTIndiana University).

Bourdieu, P. 2004. Science of Science and Reflexivity (Chicago and Cambridge, University of Chicago and Polity Press).

Brey, P. 2003. Theorizing Technology and Modernity,, in: T. Misa, P. Brey \& A. Feenberg (Eds) Modernity and Technology MIT Press).

Browne, T; Hewitt, R; Jenkins, M; Walker, R 2008 . Survey of Technology Enhanced Learning for higher education in the UK. UCISA.

Bryson, M. \& de Castell, S. 1994. "Telling Tales out of School: Modernist, Critical and Postmodern stories about Educational Technology ", Journal of Educational Computing Research, 10(3), pp. 199-221.

Carr-Chellman, A. 2006. "Desperate Technologists: Critical Issues in E-learning and Implications for Higher Education", Journal of Thought, 41(1), pp. 95-115.

Chai, C. \& S, T. 2006. Computer Supported Collaborative Learning for Knowledge Creation in: D. Fisher \& M. Swe Khine (Eds) Contemporary Approaches to Research on Learning Environments (Singapore, World Scientific ). 
Conole, G., Dyke, M., Oliver, M. \& Seale, J. 2004. "Mapping pedagogy and tools for effective learning design", Computers and Education, 43, pp. 17-33.

Coutinho, C. \& Gomes, M.J. 2006. Critical Review of Research in Educational Technology in Portugal (2000-2005Ed Media Proceedings (Orlando,

Czerniewicz, L. 2007. Understanding the field of educational technology - a review and reflectionResearch-based Elearning (Hogsback,

Czerniewicz, L., Ravjee, N. \& Mlitwa, N. 2006. ICTs and the South African Higher Education Landscape in: CHE (Ed) Higher Education Monitor (Pretoria, Council for Higher Education).

Dawson, K. \& Ferdig, R. 2006. "Commentary: Expanding Notions of Acceptable Research Evidence in Educational Technology: A Response to Schrum et al", Contemporary Issues in Technology and Teacher Education 6(1), pp. 133-142.

de Laat, M. 2006. Networked LearningPolitie Academie Netherlands).

de Laat, M., Lally, V. \& Simons, P.W., E. 2005. Questing for Coherence: a Synthesis of Empirical Findings in Networked Learning Research in Higher EducationUniversity of Southampton).

De Vaney, A. 1998. "Can and Need Educational Technology Become a Postmodern Enterprise?" Theory into Practice, 37(1), pp. 72-80.

De Vaney, A. \& Butler, R. 1996a. Voices of the Founders: Early Discourses in Educational Technology, in: D. Jonassen (Ed) Handbook of Research for Educational Communications and Technology (New York, Simon Schuster Macmillan).

De Vaney, A. \& Butler, R. 1996b. Voices of the Founders: Early discourses in educational technology, in: D. Jonassen (Ed) Handbook of research in educational technology (New York, Macmillan).

Dillenbourg, P., Baker, M., Blaye, A. \& O'Malley, C. 1996. The evolution of research on collaborative learning, in: E. Spada \& P. Reiman (Eds) Learning in Humans and Machine: Towards an interdisciplinary learning science (Oxford, Elsevier).

Dillon, P. 2004. "Trajectories and Tensions in the Theory of Information and Communication Technology in Education", British Journal of Educational Studies, 52(2), pp. 138-150.

Driscoll, M. \& Dick, W. 1999. "New research paradigms in instructional technology: an inquiry", ATR\&D 47(2), pp. 7-18.

Dueber, B. 2004. An exploration of the literature of instructional technology through citation analysis

Duffy, T. 2003. Learning Sciences and Instructional Technology Interview with Tom Duffy Indiana University Bloomington).

Edwards, T 2002 A Remarkable Sociological Imagination British Journal of Sociology of Education 23 (4), 2002

Elen, J. \& Clarebout, G. 2001. "Instructional design, towards consolidation and validation", Journal of Interactive Educational Multimedia, 3.

Ely, D. 1999. "Towards a philosophy of instructional technology: thirty years on", British Journal of Educational Technology, 30(4), pp. 305-310.

Ely, D 2000 The Field of Educational Technology: Update 2000, Eric Clearinghouse on Information and Technology 
Gamble, J 2004 retrieving the general from the particular: the structure of craft knowledge in (Eds) Muller, J; Davies, J and Morais, A Reading Bernstein, Researching Bernstein RoutledgeFalmer

Goodyear, P., Banks, S., Hodgson, V. \& McConnell, D. 2004. Research on networked learning: An overview Springer).

Gordon, J. \& Zemke, R. 2000. "The attack on ISD", Training 37(4), pp. 42-53.

Graells, P.M. 2004. The Investigation of EDucational Technology

Gunter, H 2001 Leaders and leadership in education Paul Chapman Publishing

Hedberg, J. \& McNamara, S. 2002. "Innovation and Re-Invention: A Brief Review Of Educational Technology In Australia", Educational Media International, 39(2), pp. 111-121.

Hlynka, D. 2003. "The Cultural Discourses of Educational Technology", Educational Technology, July, pp. 41-45.

Hlynka, D. \& A, Y. 1992. Postmodern Educational TechnologyERIC Digest EDO-IR-925).

Hoadley, C. 2005. The shape of the elephant: scope and membership of the CSCL community Proceedings of th 2005 conference on Computer support for collaborative learning: learning 2005: the next 10 years (Taipei, Taiwan

Hudson, A 2009 New Professionals and New Technologies, PhD Thesis Umea University

Januszewski, A. 2001. Educational Technology: The Development of a Concept (Englewood, Libraries Unlimited Inc).

Jones, C. 2004. Theory and the Practices of Learning TechnologyNetworked Learning Conference (Sheffield,

Kirby, J; Hoadley, C \& Carr-Chellman, 2005 A Instructional systems design and the learning sciences: A citation analysis Educational Technology Research and Development 53(1) pp37-48

Kozma, R. 2000. "Reflections on the State of Educational Technology Research and Development", Educational Technology Research and Development, 48(1), pp. 515.

Kuhn, T. 1962. The Structure of Scientific Revolutions (Chicago and London, University of Chicago Press).

Lellatchitch A, Mayrhofer W, Meyer M 2003 Career fields: a small step towards a grand career theory? The International Journal of Human Resource Management; Issue: 5

Lerman, S; Xu, G; Tsatsaroni, A; Williams, J.2003 A sociological description of changes in the intellectual field of mathematics education research: implications for the identities of academics in (ed.) Proceedings of the British society for research into learning mathematics $23(2)$

Lingard B.; Christie P 2003 Leading theory: Bourdieu and the field of educational leadership. An introduction and overview to this special issue International Journal of Leadership in Education 6(4), pp. 317-333(17)

Luckett, K 2009 Disciplinarity in question: comparing knowledge and knower codes in sociology Knowledge and Curriculum in Higher Education Conference, University of Cape Town 
Luppicini, R. 2005. "A Systems Definition of Educational Technology in Society", Educational Technology \& Society, 8(3), pp. 103-109.

Masterman, M. 1978. The Nature of a Paradigm, in: I. Lakatos \& A. Musgrave (Eds) Critisism and the Growth of Knowledge, Vol. 4 (Cambridge, Cambridge University Press).

Maton, K. 2000. Languages of Legitimation: the structuring significance for intellectual fields of strategic knowledge claims. British Journal of Sociology of Education 21, no.2: 147 - 167.

Maton, K. 2004. The Field of Higher Education(Cambridge, University of Cambridge).

Maton, K. 2006. On Knowledge Structures and Knower Structures. In Knowledge,Power and Educational Reform: Applying the sociology of Basil Bernstein, ed.R. Moore, M. Arnot, J. Beck, and H. Daniels, London: Routledge.

Maton, K. 2007 Knowledge-Knower Structures in Intellectual an EducationalFields. In Christie, F. and Martin, J. R. (Eds), Language, Knowledge andPedagogy: Functional linguistic and sociological perspectives (pp. 87-108).London: Continuum.

Menchik, D. 2004. "Placing cybereducation the UK classroom", British Journal of Sociology of Education, 25(2), pp. 193-213.

Merrill, D., Drake, L., Lacy, M.J. \& University, J.A.P.T.I.R.G.a.U.S. 1996. " Reclaiming Instructional Design", Educational Technology 36(5), pp. 5-7.

Moll, I., Adam, F., Backhouse, J. \& Mhlanga, E. 2007. Status Report on ICTs in Higher Education in South AfricaSAIDE).

Moore, R. \& Maton, K. 2001. Founding the sociology of knowledge: Basil Bernstein, intellectual fields and the epistemic device, in: A. Morais, I. Neves, B. Davies \& H. Daniels (Eds) Towards a Sociology of Pedagogy: The contribution of Basil Bernstein to research (New York, Peter Lang).

Moore, R. \& Muller, J. 2002. "The Growth of Knowledge and the Discursive Gap", British Journal of Sociology of Education, 23(4), pp. 627-637.

Moses, I. 1990. "Teaching, Research and Scholarship in the Different Disciplines", Higher Education, 19(3), pp. 351-375.

Perraton, H. 2000. "Rethinking the Research Agenda", International Review of Research in Open and Distance Learning, 1(1), pp. 1-11.

Pollard, C. \& Pollard, R. 2005. "Research Priorities in Educational Technology: A Delphi Study", Journal of Research on Technology in Education, 37(2), pp. 145-160.

Reigeluth, C. \& Carr-Chelman, A. 2006. A Common Language and Knowledge Base for ID? IT Forum).

Seels, B. \& Richey, R. 1994. Instructional Technology: The Definition and Domains of the Field (Washington DC, Association for Educational Communications and TEchnology).

Shurville, S., Browne, T. and Whitaker, M. 2009. Accommodating the newfound strategic importance of educational technologists within higher education: A critical literature review, Campus-Wide Information Systems, Vol. 26, No. 3, pp.201-231.

Taylor, J., Rodden, T., Anderson, A., Sharples, M., Luckin, R., Conole $<$ G \& J, S.-B. 2004. An e-learning Research AgendaEngineering and Physical Sciences Research Council). 
Tu, C.-H. \& Twu, H.-L. 2002. "Educational Technology in Taiwan", Educational Media International, 39(2), pp. 153-164.

Van der Westhuizen. 2004. Online learning in the South African context: A meta-analysis of research trends, issues and topicsSASE Conference

Weller, T \& Haider, J 2007 Where do we go from here? An opinion on the future of LIS as an academic discipline UK Aslib Proceedings: New Information Perspectives 59 (4/5) pp: 475-482

Whitworth, A. \& Benson, A. 2004. An e-learning research agendaEngineering and Physical Sciences Research Council).

Winberg, C 2007 Work-based higher degrees: responding to the knowledge needs of chemical engineers Journal of Education and Work 20(4) p319

Young, M 2006 Conceptualising Vocational Knowledge in (Eds) Young, M and Gamble $2006 \mathrm{~J}$ Knowledge Curriculum and qualifications for South African Further Education HSRC Press

Young, M. \& Muller, J. 2007. "Truth and truthfulness in the sociology of educational knowledge", Theory and Research in Education, 5(2), pp. 173-201. 